\title{
GEOMETRIA DINÂMICA NA SALA DE AULA: O DESENVOLVIMENTO DO FUTURO PROFESSOR DE MATEMÁTICA DIANTE DA IMPREVISIBILIDADE
}

\section{Dynamic geometry in the classroom: the development of prospective teachers in the face of unpredictability}

Guilherme Henrique Gomes da Silva ${ }^{1}$ - Miriam Godoy Penteado ${ }^{2}$

\begin{abstract}
Resumo: Este artigo é baseado em resultados de uma pesquisa cujo objetivo foi analisar como futuros professores de matemática, vinculados a um grupo de estudos, se apropriaram de um software de geometria dinâmica, de forma a inseri-lo em atividades de ensino. O grupo se reuniu para ler e discutir artigos científicos, explorar um software e elaborar uma oficina para alunos do Ensino Médio. Aqui são discutidas reflexões do grupo sobre os imprevistos que podem ocorrer quando o professor atua num ambiente de aprendizagem baseado em Tecnologia da Informação e Comunicação (TIC). São apresentados episódios que ilustram como uma zona de risco pode se constituir numa zona de possibilidades para aprendizagem da docência. O grupo fornece estímulo e condições para se refletir e enfrentar os imprevistos decorrentes de um ambiente computacional, o que impulsiona o movimento para o desenvolvimento profissional.
\end{abstract}

Palavras-chave: Ensino Médio. Ensino de matemática. Geometria dinâmica. Tecnologia da informação e comunicação. TIC.

\begin{abstract}
This paper presents the result of a research aiming to analyze how a study group, of prospective mathematics teachers, used dynamic geometry software in planning activities for a teaching practice. Before practicing with students, the group read and discussed papers from journals, explored Geogebra, dynamic geometry software, and planned a workshop to be held with students at high school level. A special highlight is given to the unpredictability which occurs in a ICT-based environment, and how this establishes a risk zone. Thus there are both technical and mathematical content related risks. The results show that a collective theoretical study was essential for the prospective teachers not to be paralyzed when facing unpredictability. Episodes are discussed illustrating how a risk zone can turn into a fruitful learning environment. The group provides conditions for reflecting and facing the unpredictability of a computer-based environment, stimulating professional development.
\end{abstract}

Key words: High school. Mathematics teaching. Dynamic geometry. Information technology and communication. ICT.

\footnotetext{
${ }^{1}$ Instituto de Ciências Exatas, Universidade Federal de Alfenas (UNIFAL-MG), Rua Gabriel Monteiro da Silva, 700, Centro, Alfenas, MG, Brasil, CEP 37130-000. <guilhermehgsilva@gmail.com>.

${ }^{2}$ Instituto de Geociências e Ciências Exatas, UNESP - Univ Estadual Paulista, Campus de Rio Claro,

Departamento de Matemática, SP, Brasil.
} 
Silva, G. H. G.; Penteado, M. G.

\section{Introdução}

Este artigo apresenta resultados de uma pesquisa relacionada ao uso de Tecnologia da Informação e Comunicação (TIC) no ensino e aprendizagem da geometria plana, cujo foco foi analisar as reflexões feitas por participantes de um grupo de estudos, formado por alunos de um curso de licenciatura em matemática, no movimento de elaborar e desenvolver atividades de geometria dinâmica para estudantes do Ensino Médio. O objetivo foi analisar como esse grupo de estudos se apropriava de um software de geometria dinâmica de forma a inserilo em sua futura prática docente, identificando suas potencialidades pedagógicas. Também fez parte do objetivo conhecer a natureza das dificuldades que surgiram durante os estudos, a preparação e o desenvolvimento de atividades em sala de aula, e como o grupo serviu de apoio na tomada de decisão.

Foi utilizada uma abordagem qualitativa de pesquisa tendo em vista que o interesse era compreender elementos de uma situação envolvendo o cotidiano do futuro professor de matemática, além de sentimentos, crenças, motivações e atitudes individuais. Segundo Denzin e Lincoln (2006), esta metodologia localiza o observador no mundo, sendo composta por um conjunto de práticas materiais e interpretativas capazes de fornecer visibilidade ao mundo. Para os autores, tais práticas "transformam o mundo em uma série de representações, incluindo as notas de campo, as entrevistas, as conversas, as fotografias, as gravações e os lembretes" (DENZIN; LINCOLN, 2006, p. 17). Além disso, a pesquisa qualitativa envolve o estudo do uso e a coleta de uma vasta gama de materiais empíricos, como, por exemplo: o estudo de caso, a introspecção, história de vida, entrevistas, artefatos, textos observacionais, entre outros, que, de acordo com os autores, descrevem momentos e significados na vida dos indivíduos. Dessa forma "os pesquisadores dessa área utilizam uma ampla variedade de práticas interpretativas interligadas, na esperança de sempre conseguir compreender melhor o assunto que está ao seu alcance" (DENZIN; LINCOLN, 2006, p. 17).

De forma a alcançar os objetivos da pesquisa, criou-se um grupo de estudos com seis alunos do segundo ano do curso de licenciatura em Matemática: André, Ana Lígia, Ester, Welder, Silmara e Keila ${ }^{3}$, para elaborar uma série de atividades investigativas utilizando o software Geogebra (2011) e estudar as possibilidades de seu uso em aulas de Matemática na escola básica.

Foram realizados oito encontros com os licenciandos, dos quais dois foram destinados à realização de uma oficina para alunos de uma escola estadual de nível médio. Nos encontros os participantes discutiam artigos científicos sobre temas como o uso de computadores na educação e investigação matemática em sala de aula, além de conteúdos específicos da geometria plana. Após a leitura prévia e discussão, o grupo explorava o software Geogebra (2011) e, baseado na teoria estudada, elaborava atividades de geometria dinâmica com uma perspectiva investigativa.

Os dados da pesquisa consistiram: dos registros em vídeo dos encontros realizados, dos registros escritos feitos pelo grupo, e das notas de observação feitas no caderno de campo

${ }^{3}$ Nomes fictícios. 
de um dos pesquisadores que esteve inserido no contexto da pesquisa participando como membro do grupo de estudos.

O processo de categorização dos dados ocorreu após a transcrição de todas as gravações e constante leitura das mesmas e dos outros instrumentos utilizados. Como os encontros não possuíam um roteiro específico, todas as discussões do grupo foram separadas por temas. Após diversas reformulações, cinco categorias foram definidas, que dizem respeito às reflexões dos participantes do grupo sobre:

1. Atividades investigativas;

2. Imprevisibilidade em um ambiente baseado em TIC;

3. Design do software Geogebra;

4. Contribuições do grupo de estudos em relação a: estudo de teorias; suporte para atuação na escola; suporte para a elaboração de atividades investigativas; prática docente; estímulo na busca por novos conhecimentos;

5. Desenvolvimento profissional dos participantes do grupo de estudos.

Neste artigo são discutidas as reflexões do grupo no que diz respeito aos momentos imprevistos que surgiram durante o desenvolvimento da oficina na escola.

\section{Imprevisibilidade e o uso de TIC}

É cada vez maior a quantidade de softwares que podem ser utilizados para o estudo de matemática numa perspectiva diferente do que usualmente caracteriza uma aula dessa disciplina, ou seja, o professor explica a matéria e propõe exercícios que são resolvidos pelos alunos e corrigidos na lousa. A literatura sobre Educação Matemática relaciona a Tecnologia da Informação e Comunicação (TIC) com temas como modelagem matemática, resolução de problemas e outras metodologias que pressupõem um papel mais ativo do aluno em seu processo de aprendizagem. Existem softwares apropriados para o estudo de tópicos como: funções, probabilidade, álgebra, geometria, exploração de gráficos, entre outros. No que diz respeito à geometria, existem ambientes que proporcionam, aos estudantes, experiências que dificilmente seriam feitas com outras mídias como o lápis e o papel: são os ambientes de geometria dinâmica.

Tal ambiente pode ser definido como um software cuja característica principal é a possibilidade de 'arrastar' as construções geométricas com o cursor do mouse, ao mesmo tempo em que as medidas são atualizadas. Goldenberg, Scher e Feurzeig (2008) afirmam que os ambientes de geometria dinâmica permitem aos estudantes criarem construções geométricas e manipulá-las facilmente. Para esses autores, o arrastar permite ao usuário mover certos elementos de um desenho e observar as alterações correspondentes. Nesse processo, o desenho se deforma continuamente mantendo as relações especificadas como essências na construção original.

Apesar de diversas pesquisas mostrarem que a TIC, quando trabalhada de forma a ajudar o aluno na construção de seu conhecimento matemático, possui um grande potencial para a educação, sua utilização nem sempre é bem vista pelos docentes, pois significa a necessidade de assumir riscos durante a aula. Conforme Penteado (2001), uma razão para isso é que engajar-se em trabalhos que fazem uso de tecnologia informática é algo como sair de uma 
Silva, G. H. G.; Penteado, M. G.

zona caracterizada pelo conforto proporcionado pela previsibilidade e o controle da situação, para atuar numa zona de risco na qual impera o imprevisto.

De acordo com Penteado (2001), os ambientes baseados em TIC propiciam, com mais frequência, tais imprevistos, já que o professor pode se deparar com situações como, por exemplo: mau funcionamento de um computador ou um apertar de teclas pelos alunos que leve a uma situação não esperada. Nesse cenário, o professor está mais propício a sair de uma zona de conforto, caracterizada pela certeza e previsibilidade do ambiente, e entrar em uma zona de risco, que requer tomada de decisão sobre situações nunca antes experimentadas. De acordo com Penteado e Skovsmose (2009), uma zona de risco, apesar de parecer um momento negativo, é, na verdade, um espaço que precisa ser explorado pelo professor para ampliar as possibilidades de aprendizagem dos alunos.

Para Miskulin e Piva Jr. (2007), as práticas pedagógicas, de uma forma planejada e sistemática, com o uso da TIC permitem que os alunos desenvolvam uma competência de trabalho autônomo, pois se deparam, desde muito novos, com várias ferramentas de investigação. Além disso, a TIC propicia um acesso rápido à informação e permite uma prática de confrontação, verificação, organização, seleção e estruturação, já que as informações nem sempre se encontram em uma mesma fonte. Os autores destacam também que essas práticas permitem: o desenvolvimento das competências de análise e de reflexão, abertura ao mundo, organização do pensamento, trabalho simultâneo com colegas situados em diferentes partes do mundo, organização espacial e uma vasta gama de possibilidades.

A TIC pode ser utilizada de forma confortável pelo professor, ou seja, por meio de atividades do tipo tutorial ${ }^{4}$. Porém, como afirma Valente (1993), esse método não usufruirá vantagem educacional da TIC, pois é apenas uma versão computadorizada do que já ocorre usualmente na escola. Este não é o tipo de uso defendido aqui.

\section{Cenário de investigação no Geogebra}

Os licenciandos trabalharam com o software Geogebra (2011), que é um programa com licença livre, que permite o trabalho com geometria, cálculo, álgebra e tabelas. Nesse programa, todo objeto possui seu representante geométrico e algébrico.

O Geogebra possui duas janelas de trabalho: a janela geométrica e a janela de álgebra. A janela geométrica é o local onde os objetos são construídos. Nela, é possível colorir figuras, aumentar a espessura das linhas, medir ângulos e distâncias, habilitar coordenadas cartesianas e polares etc. $\mathrm{Na}$ janela de álgebra, é possível visualizar a representação algébrica de todo objeto construído. Essa dupla representação de objetos é a mais notável característica que o programa possui.

O software apresenta, ainda, um campo de entrada de comandos, em que é possível escrever coordenadas, equações, e funções, de tal forma que, pressionando a tecla enter, eles são exibidos imediatamente na tela. O Geogebra admite também expressões como: $g: 3 x+4 y$

\footnotetext{
${ }^{4}$ Trabalhando em forma de tutorial, de acordo com Valente (1993), o computador passa a ter um papel de máquina de ensinar, não usufruindo de todo o potencial que essa ferramenta possui. 
Geometria dinâmica na sala de aula: ...

$=7$ ou: $c:(x-2)^{2}+(y-3)^{2}=25$, e oferece uma variedade de comandos, incluindo cálculo de derivadas e integrais. A Figura 1 mostra a área de trabalho do programa.

Figura 1. Tela do software Geogebra

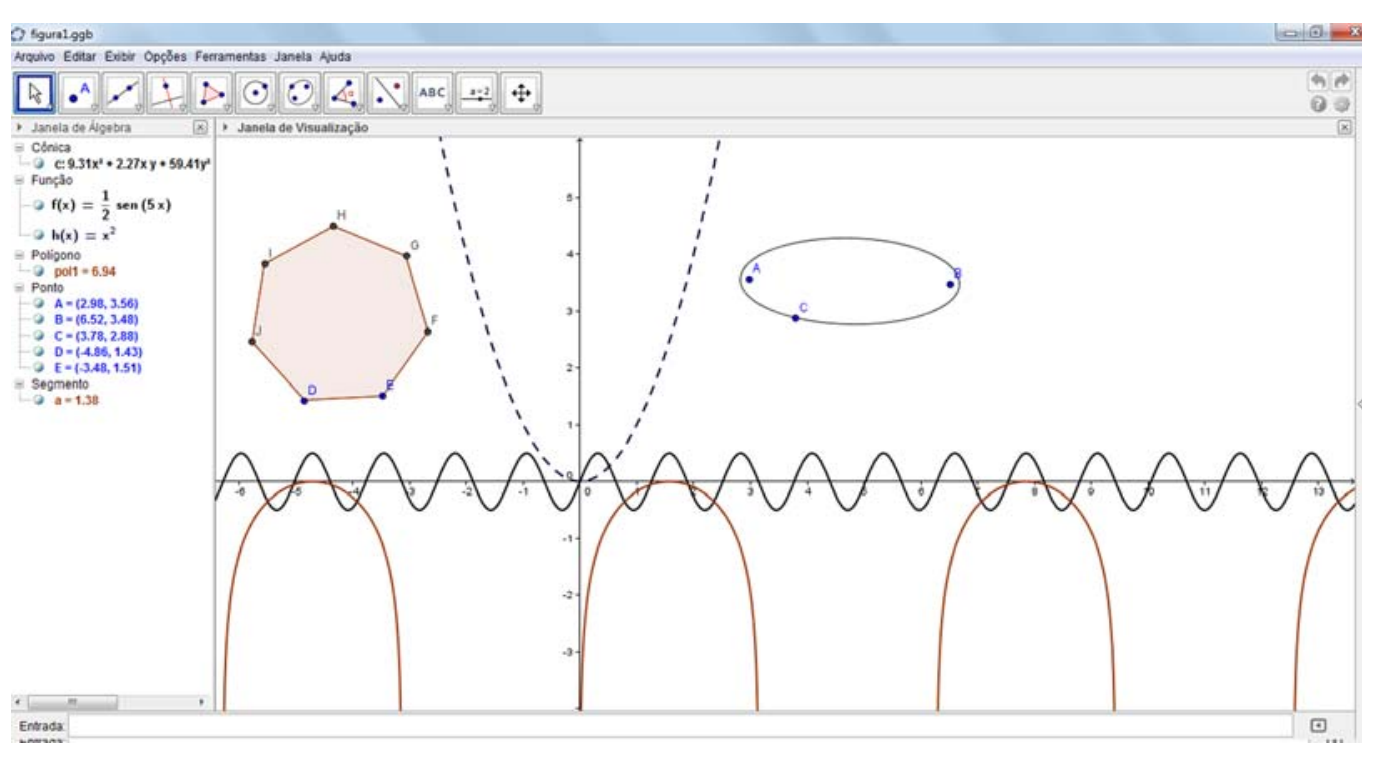

Fonte: Elaborado pelos autores

Após alguns momentos de exploração livre do software, o grupo dedicou-se à elaboração de atividades de caráter investigativo, que são constituídas por tarefas que convidam o estudante a formular questões e explicações para o que se está fazendo. Atividades investigativas diferenciam-se das que tradicionalmente ocorrem na aula de matemática, pois privilegiam processos matemáticos como, por exemplo: procurar regularidades, formular, testar e provar conjecturas, refletir e generalizar. Também faz parte o processo de refutação de uma conjectura e sua reformulação. Dessa forma, assemelham-se aos procedimentos utilizados por matemáticos profissionais na produção de novos conhecimentos.

No caso em foco, baseado na proposta de Skovsmose (2008), o grupo utilizou-se de perguntas do tipo "o que acontece se..." para orientar o processo de investigação do estudante. O Quadro 1 traz um exemplo de uma atividade elaborada pelo grupo, que constituiu um cenário de investigação no Geogebra.

Trabalhar em um cenário de investigação requer, do professor e de seus alunos, um senso investigativo, ou seja, eles devem procurar conhecer o que não sabem. Nesses cenários, os alunos são convidados a trabalhar como matemáticos profissionais. Isso não significa que alunos estarão construindo novos conhecimentos ou teoremas, mas terão possibilidade de explorar e formular suas próprias conjecturas, lançar seus próprios contraexemplos, apresen- 
Silva, G. H. G.; Penteado, M. G.

tar resultados de sua investigação aos colegas e professores, e argumentar sobre fatos matemáticos que, na maioria das vezes, são vistos como irrefutáveis ou inquestionáveis. Dessa forma, os alunos são convidados a aprender matemática fazendo matemática.

Quadro 1. Atividade elaborada pelo grupo de estudos.

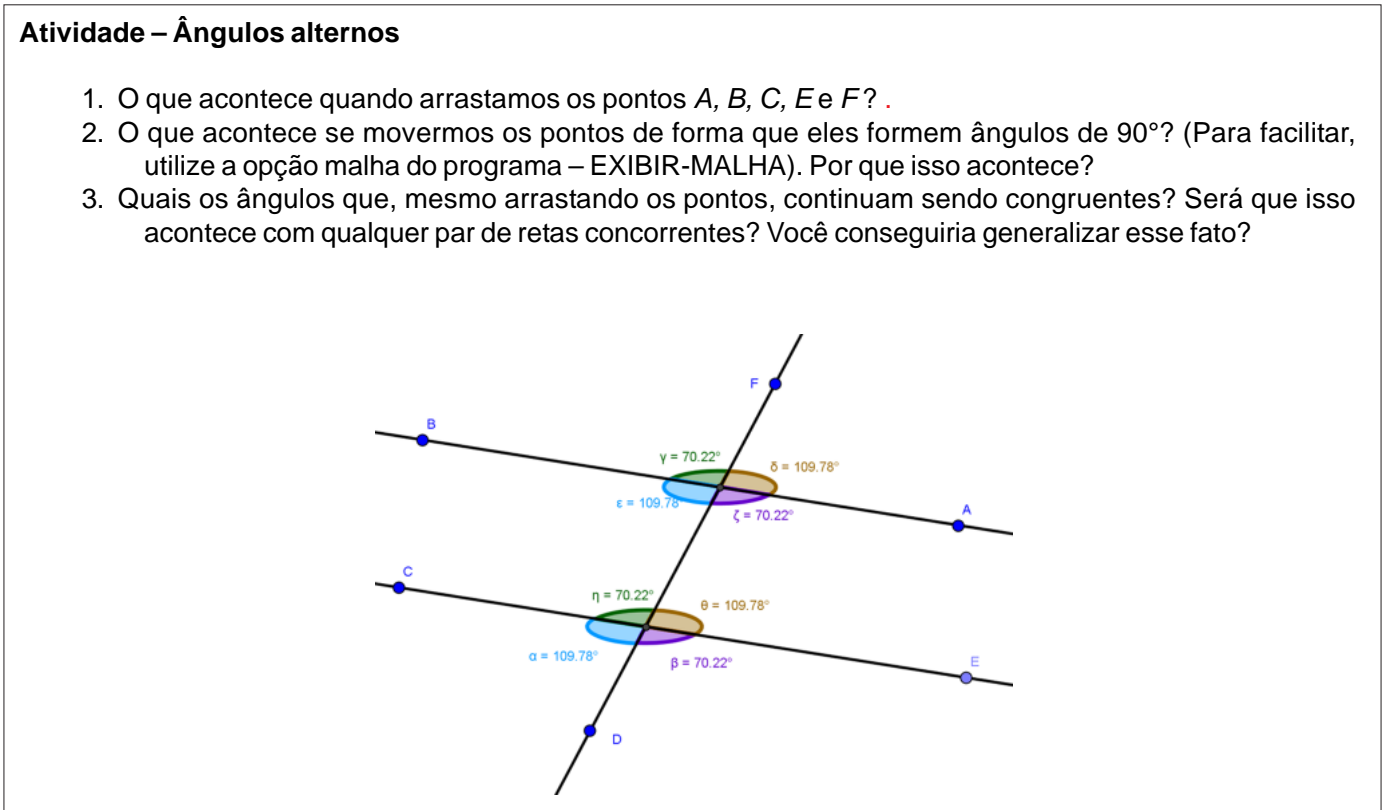

Fonte: Elaborado pelos autores

\section{“Deixar rolar" - lidando com o imprevisto durante o uso do software}

Uma das dificuldades que surge quando se utiliza a TIC em sala de aula é de ordem técnica: teclado que se danifica, cabo que se desconecta, tela que se desliga, mouse que não funciona. Geralmente, os professores não estão preparados para lidar com tais situações, o que pode comprometer o bom andamento da aula.

Nas oficinas ministradas pelo grupo, logo no primeiro dia de trabalho surgiu uma dificuldade dessa natureza, que quase impediu a realização de tudo que havia sido planejado. O sistema operacional dos computadores da escola era diferente do sistema operacional que o grupo utilizou para se preparar e, sendo assim, ninguém conseguia abrir os arquivos com as atividades no Geogebra. Isso deixou o grupo muito nervoso e requereu um tempo extra para descobrir como lidar com o novo sistema de forma a iniciar as atividades. Outra surpresa desagradável foi que o mouse de uma das duplas parou de funcionar. 
"As meninas que estavam sentadas atrás, o mouse delas deu problema. No começo elas estavam fazendo. Então eu vi que elas não escreviam nada porque elas não faziam mais nada, ai eu perguntei o que estava acontecendo. Elas disseram, "está igual" (em relação à atividade). 'Mas vocês mexeram, usaram o mouse para arrastar?'. Elas falaram 'acho que o mouse não está funcionando'. Então eu tirei o mouse do computador do lado e passei para o delas. Ai eu pensei em não deixar o aluno perder o foco do que ele estava fazendo. Às vezes diante do equipamento que está dando problema pode ser uma coisa que vai desmotivar o aluno. Às vezes você está prestando atenção se todas as ferramentas estão rendendo o que você espera. Acho que o mais interessante para quem vai aplicar as atividades é se deparar com o imprevisto e saber improvisar, ser criativo para sair dele, porque a hora que a menina falou 'meu mouse não está funcionando', na hora eu corri atrás e coloquei para ela. Acho que o mais interessante é a gente trabalhar essa criatividade na bora." (André)

Apesar de parecer um problema ligeiramente simples de resolver, em muitas escolas não há um técnico a quem recorrer em situações como essa e, em alguns casos, os professores não possuem conhecimentos mínimos sobre informática, fazendo com que, por exemplo, a simples troca de um mouse por outro se torne um obstáculo para o bom andamento da aula. Como fazer uma investigação com um software de geometria dinâmica se o mouse não funciona? Se não há como arrastar um objeto na tela, não há como investigar suas propriedades geométricas (PENTEADO; SKOVSMOSE, 2009).

Além dos problemas de ordem técnica, surgiram outros decorrentes das atividades propostas. É importante observar que o grupo leu e discutiu sobre a constituição de uma zona de risco e procurou antecipar muitas situações durante a preparação das atividades, buscando minimizar o imprevisto. Porém, como já anunciado na teoria, foi impossível prever o que ocorreria com o uso do software. Um exemplo ocorreu quando os alunos investigavam a propriedade de que, em duas retas concorrentes, ângulos opostos pelo vértice possuem mesma medida. Conforme ilustra a Figura 2, a ideia era que os pontos $A, B, C$ e $D$ fossem arrastados pela tela do computador para comprovar que tal propriedade era válida para qualquer posição das retas.

Aparentemente, nada poderia sair errado com essa investigação, porém um dos estudantes arrastou o ponto $C$ de forma que ele ficou entre os pontos $E$ e $D$ e o software passou a indicar medidas diferentes para os ângulos opostos, ou seja, a propriedade deixou de valer (Figura 3).

O que fazer diante disso? O professor sabe que a propriedade é válida sempre, mas a tela do computador mostra algo que contradiz isso. $\mathrm{O}$ trecho a seguir revela o procedimento adotado pelo participante que conduzia a aula.

André:- Na hora que eu percebi o problema, comecei a conversar com a dupla e eu ia questionando para ver o que estava acontecendo.

André: - Que valor está dando ai?

Dupla: - ah, é "tanto". 
Silva, G. H. G.; Penteado, M. G.

Figura 2. Atividade elaborada pelo grupo.

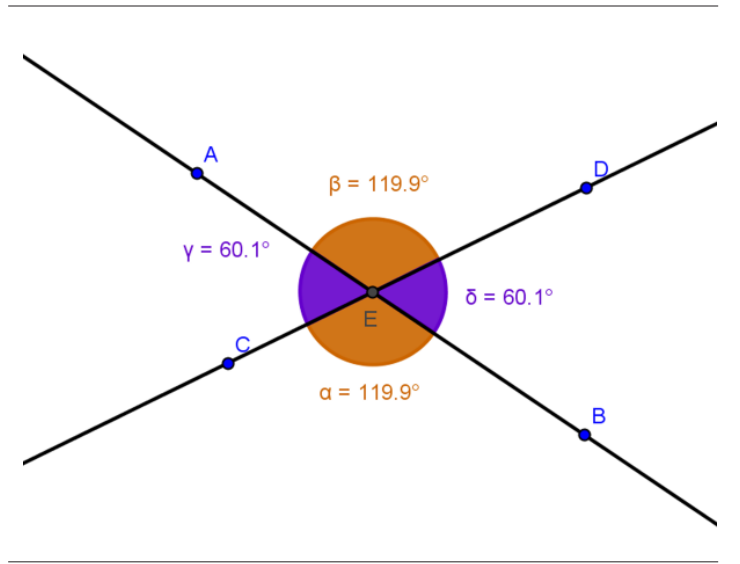

Fonte: Elaborado pelos autores

Figura 3. Atividade elaborada pelo grupo.

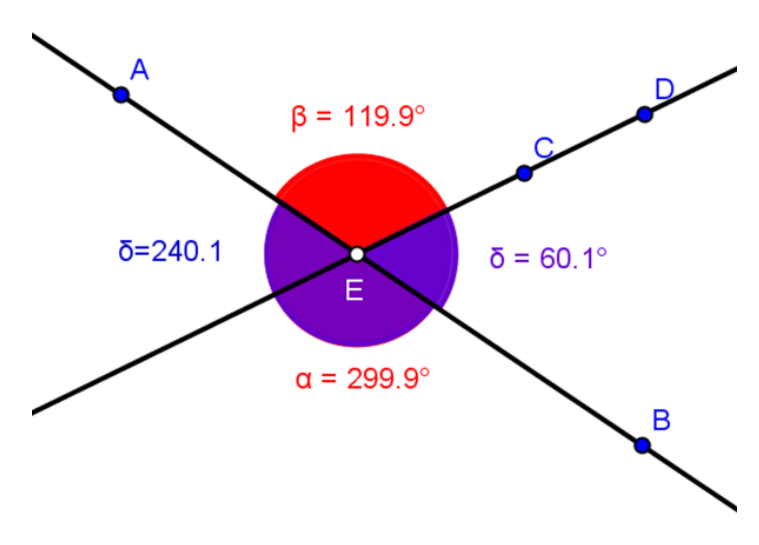

Fonte: Elaborado pelos autores

André: - e qual era o valor inicial?

Dupla: - a, era "tanto"

André: - qual era a diferença do maior para o menor?

Dupla: - é $180^{\circ} \ldots$

André: - $180^{\circ}$ não são dois ângulos retos, então é uma meia circunferência

Dupla: - é verdade, o ângulo passou daqui para baixo...

André: - Então eles queriam enunciar isso. Ai eu disse que isso na verdade é porque o software está fazendo a leitura do ângulo $A \hat{E} C$, e não importa onde o ponto $A$ estiver, nessa reta ou nessa reta (aqui ele quis dizer na semi reta $\mathrm{E} A$ ou entre os pontos E e B na semi reta EB). 
Pesquisador: - Você falou isso para eles?

André: - Isso. Ele vai ler esse ângulo, a gente marcou o ângulo central, mas o ponto é deslocável. Você pode deslocá-lo pela reta. A dupla estava motivada para fazer a conjectura de uma maneira coerente, com uma linguagem matemática. E para uma aula investigativa isso é muito bom.

Mesmo que o software possa ter confundido os alunos, André mostrou outra possibilidade para que pudessem explorar um acontecimento novo que surgiu em decorrência da atividade. Embora não tivesse dado continuidade ao processo de investigação, sua fala é um indício de que percebeu potencialidade de uma zona de risco para a aprendizagem matemática no sentido do que discutem Penteado e Skovsmose (2008).

No segundo dia da oficina, as responsáveis pela dinâmica foram Ana Lígia e Ester. Elas também se depararam com uma situação imprevista no momento em que alunos investigavam o resultado da soma dos ângulos internos de um triângulo.

O objetivo era que eles arrastassem os vértices e usassem uma calculadora de mão para somar as medidas dos ângulos que apareciam na tela, conforme movimentavam a figura, e concluir que o resultado seria sempre 180 graus. Atividade muito simples quando foi planejada, porém, por diversas vezes, a calculadora mostrava um resultado diferente de 180 graus. A propriedade era válida quando se utilizava a ferramenta de somar do próprio Geogebra. Porém, deixava de valer quando a soma era feita na calculadora manual. Vários alunos até utilizaram a calculadora dos celulares para confirmar o fato. Ana Lígia e Ester não esperavam por isso, mas lidaram bem com a situação.

Ester: - Eu fiquei meio sem saber o que fazer. Eu fiquei esperando para ver o que a Ana Ligia falaria para gente falar a mesma coisa se não a gente iria entrar em contradição.

Pesquisador: - Ela falou que era por causa da casa decimal do programa não é? Ester: - Sim. Então um aluno falou assim para mim: 'ah, mas então não é sempre que vai dar'. Então en falei: 'não, é que aqui o programa, por causa das casas decimais e tal'. Daí ele falou 'a, então tá bom, mas se for no papel vai dar não é?

Pesquisador: - Vocês viram como é. Ninguém esperava isso, foi uma coisa inesperada.

Ana Ligia: - A menina somou na calculadora e não deu. Daí ela somou no celular também para ver que não ia dar, mas essas coisas sempre acontecem. Nem sempre tudo vai ser perfeito. Pode ser que aconteça.

Pesquisador: - Mas o que vocês sentiram na hora? Deu vontade de recuar ou de 'deixar rolar'? Eu percebi que a Ana Ligia chamon a atenção da sala e disse 'olha pessoal, aconteceu isso aqui com essa dupla, aconteceu com mais alguém?'. Então todo mundo ficou atento.

Silmara: - Eu percebi isso que ela falou. Um grupo falou que não tinha dado certo. Dai os outros grupos que tinham dado certo a atividade, que a soma tinha dado $180^{\circ}$, começaram a mexer para não dar $180^{\circ}$. Eles começaram a arrastar para não dar $180^{\circ}$. Em um grupo o resultado foi $179.99^{\circ}$. 
Silva, G. H. G.; Penteado, M. G.

Welder: - A Ana Ligia tinha acabado de falar 'olha, pode ser que aconteça de

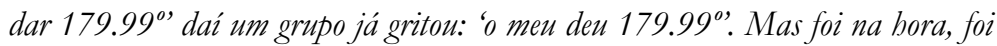
bem em cima, eu estava olhando para Ligia, vi eles mexendo enquanto ela estava falando e assim que ela acabou de falar eles tinham acabado de somar.

Ana Lígia e Ester perceberam rapidamente que o software utiliza apenas cinco casas decimais e discutiram, com a classe, esta aparente falha. Considerando a situação, elas poderiam ter utilizado esse episódio para ir um pouco mais além, introduzindo uma discussão sobre demonstração matemática, que, nesse caso, serviria como mais uma forma de convencimento. Lourenço (2002) afirma que figuras e construções podem ser ilusórias para o aluno e, em alguns casos, atrapalham o processo dedutivo. Dessa maneira, essa situação seria apropriada para discutir, com os alunos, o papel da demonstração no processo de generalização de resultados.

Durante os encontros do grupo e o desenvolvimento da oficina na escola, foi possível notar um discurso na fala dos participantes em sintonia com a teoria de que a zona de risco pode oferecer possibilidades; e, quando ela é encarada de forma construtiva, tanto professores quanto alunos podem caminhar para novas aprendizagens. Certamente, esse discurso foi influenciado pela leitura que fizeram do texto de Borba e Penteado (2001, p. 61), que afirmam não ser "possível manter-se numa zona de risco sem se movimentar em busca de novos conhecimentos".

André: - [...] quanto mais a gente minimiza, mais a gente é exposto a um erro de maior intensidade, porque se a gente minimiza ao máximo alguém vai pensar em alguma coisa que não tínhamos pensado e essa coisa será muito complicada.

Pesquisador: - Vocês estão vendo a zona de risco como um erro então?

André: - Não como um erro, mas como um momento construtivo. Pode ser que você erre naquele momento ou não saiba, mas você como professor acaba correndo atrás para aprender. Isso é aprender através de uma situação que você não esperava. Camila: - Não é um erro, é uma coisa que aconteceu que o aluno descobriu e que você não esperava. [...] Mas quando isso acontece você tem que mostrar ao aluno que você quer resolver. Por exemplo, 'ah vamos ver o que acontece então se fizermos isso' on 'vamos ver por que aconteceu isso'.

Silmara: - Quando eu mudei a atividade para que os ângulos não mudassem, eu tentei limitar o risco, mas acho que isso é mais medo porque a gente ainda não enfrentou uma sala de aula, ainda mais levando eles para o computador.

Welder: - Tem que deixar rolar, para ver se clareia alguma coisa para gente e se o aluno consegue resolver.

O fato de terem discutido o conceito de zona de risco durante as reuniões do grupo trouxe uma tranquilidade maior no momento da realização da oficina. Dessa forma, quando os imprevistos surgiram, eles tinham como nomear a situação e sabiam que o seu potencial se realizaria se não tentassem paralisar o movimento, ou seja, se deixassem rolar, como disse Welder. Para Borba e Penteado (2001), com ousadia e flexibilidade, os professores podem avançar 
nesta área de indeterminação para reorganizarem as atividades na medida do necessário, ou seja, "mudam as rotinas e, antes de tudo, abrem-se para um processo de negociação com os alunos e com outros que atuam no cenário escolar" (BORBA; PENTEADO, 2001, p. 64).

Nos episódios das oficinas, foi possível explicar os imprevistos quase que imediatamente, porém, nem sempre é assim. Borba e Penteado (2001) apresentam um caso de um professor orientando uma investigação sobre elipse e hipérbole usando a ferramenta de lugar geométrico de um software de geometria dinâmica. O professor teve o domínio das situações que ocorriam em praticamente toda aula, até que uma aluna solicitou sua presença para mostrar que a imagem exibida na tela do computador não era nem uma elipse nem uma hipérbole. Mesmo parando para analisar e discutir a situação com a classe, não se conseguiu uma explicação plausível para o que se via na tela. O professor sabia que aquela imagem não correspondia à definição de elipse ou hipérbole, mas não conseguia descobrir como o software estava operando para responder daquela forma. Foi preciso um tempo extra-aula para que a investigação fosse feita com outros softwares de geometria dinâmica, até que o professor percebesse que a aluna tinha definido o lugar geométrico como se fosse de uma circunferência e o programa em uso fornecia várias circunferências concêntricas. $\mathrm{O}$ fato foi esclarecido e retomado no próximo encontro. Se, nesse caso, o professor não tivesse experiência, certamente essa situação seria um motivo de paralisação da aula e inibição de continuidade de uso de TIC para ensinar matemática.

Os participantes do grupo disseram que, em casos como esse, é preciso cuidado do professor para envolver os alunos na discussão, pois, caso contrário, pode haver tumulto na sala de aula. André observa que o professor não tem obrigação de saber tudo, mas tem de estar bem preparado, pois, se ocorrerem muitas situações de paralisia, o estudante pode perder a confiança no professor e o interesse pela aula. Dessa forma, ao invés de possibilidade, uma zona de risco tornar-se-ia um obstáculo para a aprendizagem.

\section{Considerações finais}

Neste artigo, defende-se a ideia de que aulas de matemática com uso de softwares de geometria dinâmica são mais propícias para ocorrerem imprevistos do que as que utilizam recursos tradicionais, caracterizando, assim, o que a literatura denomina de uma zona de risco. Defende-se, também, que é o movimento entre uma zona de conforto e uma zona de risco que trará maior possibilidade de aprendizagem dos alunos e, também, dos professores.

Foram apresentados episódios oriundos de atividades de um grupo de estudo formado por alunos de licenciatura em matemática, destacando como o estudo teórico serviu de apoio para a atuação durante o desenvolvimento de oficinas com estudantes do Ensino Médio.

As experiências de aproximação entre teoria e prática, nos cursos de licenciatura, possibilitam uma reflexão sobre a prática e um posicionamento teórico sobre o ensino e aprendizagem da Matemática. Se o desenvolvimento das atividades nas oficinas elaboradas pelo grupo tivesse ocorrido muito tempo depois de realizado o estudo teórico, os futuros professores teriam mais dificuldades para realizar tais reflexões. Isso sugere a importância de que cursos de licenciatura em Matemática propiciem esse tipo de abordagem. Como afirma Ortale 
Silva, G. H. G.; Penteado, M. G.

(2007, p. 46), "uma das tarefas dos cursos de licenciatura, e também de formação contínua, é criar oportunidades para que os alunos reflitam sobre as possíveis origens das escolhas metodológicas realizadas em sala de aula.” De acordo com Tanuri et al. (2003, p. 224):

[...] o conceito de prática não implica em uma contraposição à teoria, ao contrário, pressupõe com esta uma íntima vinculação. É desta forma que a teoria passa a contribuir com a atividade prática. Essa contribuição deverá ocorrer na medida em que a teoria passa a ajudar no esclarecimento da situação onde a prática se desenvolve. Ela contribui na interpretação de dados, elementos e condições da realidade que nos apresenta e que pretendemos reforçá-la ou transformá-la. No entanto, a atividade prática se não orientada por uma intenção e sem a reflexão teórica, se não conduzida a partir de um projeto, esclarecido pela teoria, ela se mantém mecânica, cega, sem direção e, por isso, sem eficácia.

Os resultados da pesquisa permitem afirmar que a teoria estudada iluminou o caminho para a prática dos participantes, e que a participação em grupo de estudos traz contribuições importantes para os licenciandos no que diz respeito à sua formação profissional. Todos ampliaram seus conhecimentos didáticos acerca dos conteúdos utilizados nas atividades elaboradas e também tiveram contato com a possibilidade de explorar a tecnologia da informação e comunicação com alunos do Ensino Médio. Apesar disso, cada participante assimilou esses saberes de uma forma particular. Isso decorre, de acordo com Ferreira (2006): da experiência, do estágio de vida, da história pessoal e das características pessoais de cada participante.

Para encerrar, é importante destacar que foi no coletivo do grupo que os estudantes de licenciatura se prepararam e encontraram suporte para atuar diante dos imprevistos. $\mathrm{O}$ grupo estudou o software, preparou e desenvolveu atividades com alunos, e refletiu sobre a prática à luz da teoria. Isso reforça a importância do trabalho coletivo para atuar em uma zona de risco, já que, de acordo com Borba e Penteado (2001), o trabalho individual contribui para que os professores permaneçam em uma zona de conforto, estimulando uma estagnação. Para os autores, "é o pensar e agir coletivo que poderão impulsionar e manter o professor numa zona de risco de forma que ele possa usufruir o seu potencial de desenvolvimento" (BORBA; PENTEADO, 2001, p. 68). Quando o professor vincula-se a um grupo, ele consegue estímulo e condições para refletir e encarar os imprevistos decorrentes de um ambiente computacional, o que impulsiona o movimento para o desenvolvimento profissional. 
Geometria dinâmica na sala de aula: ...

\section{Referências}

BORBA, M. C.; PENTEADO, M. G. Informática e educação matemática. 2. ed. Belo Horizonte: Autêntica, 2001.

DENZIN, N. K.; LINCOLN, Y. S. O planejamento da pesquisa qualitativa: teorias e abordagens. Porto Alegre: Artmed, 2006. v. 2.

FERREIRA, A. C. O trabalho colaborativo como ferramenta e contexto para o desenvolvimento profissional: compartilhando experiências. In: NACARATO, A. M.;

PAIVA, M. A. V. (Org.). A formação do professor que ensina matemática: perspectivas e pesquisas. Belo Horizonte: Autêntica, 2006. p.149-166.

GEOGEBRA: dynamic mathematics for schools. Version 4.0. Salzburg: Department of Mathematics, University of Salzburg, 2011. Disponível em: <www.geogebra.org>. Acesso em: 20 jan. 2011.

GOLDENBERG, E. P.; SCHER, D.; FEURZEIG, N. What lies behind dynamic interactive geometry software? In: BLUME, G. W.; HEID, M. K. (Ed.). Research on technology and the teaching and learning of matematics: cases and perspectives. Charlotte: Information Age, 2008. v. 2. p. 53-88.

LOURENÇO, M. L. A demonstração com informática aplicada à educação. Bolema, Rio Claro, v.15, n. 18, p. 100-111, 2002.

LÜDKE, M.; ANDRÉ, M. E. D. A. Pesquisa em educação: abordagens qualitativas. São Paulo: EPU, 1986.

MISKULIN, R. G. S.; PIVA JR., D. A relação entre aprendizagem significativa e aprendizagem colaborativa: um estudo de caso utilizando TICs e mapas conceituais. In: MENDES, J. R.; GRANDO, R. C. (Org.). Múltiplos olhares: matemática e produção de conhecimento. São Paulo: Musa, 2007. p. 136-150.

ORTALE, F. L. Caminhos para a formação do professor reflexivo. In: GRANVILLE, A. (Org.). Teorias e práticas na formação de professores. Campinas: Papirus, 2007. p. 4166.

PENTEADO, M. G. Computer-based learning environments: risks and uncertainties for teacher. Ways of Knowing Journal, Brighton, v. 1, n. 2, p. 23-35, 2001.

PENTEADO, M. G.; SKOVSMOSE, O. Riscos trazem possibilidades. In: SKOVSMOSE, O. Desafios da reflexão em educação matemática crítica. Campinas: Papirus, 2008. p. 41-50.

How to drag with a worn-out mouse? Searching for social justice through collaboration. Journal of Mathematics Teacher Education, Dordrecht, v. 12, n. 3, p. 217-230, 2009. 
Silva, G. H. G.; Penteado, M. G.

SILVA, G. H. G. Grupos de estudo como possibilidade de formação de professores de matemática no contexto da geometria dinâmica. 2010. 191 f. Dissertação (Mestrado em Educação Matemática) - Instituto de Geociências e Ciências Exatas, Universidade Estadual Paulista, Rio Claro, 2010.

SKOVSMOSE, O. Desafios da reflexão em educação matemática crítica. Campinas: Papirus, 2008.

TANURI, L. M. et al. Pensando a licenciatura na Unesp. Nuances: estudos sobre educação, Presidente Prudente, v. 9, n. 9/10, p. 211-229, 2003.

VALENTE, J. A. Computadores e conhecimento: repensando a educação. Campinas: Unicamp, 1993.

Artigo recebido em 27/07/12. Aceito em 31/10/12. 